\title{
WHAT DO WE KNOW ABOUT STOCK MARKET "EFFICIENCY"?
}

\author{
Ray Ball
}

William E. Simon Graduate School

of Business Administration

University of Rochester

Rochester, NY 14618

USA

KEYWORDS/ABSTRACT: anomalies / capital asset pricing model / efficient markets / research design / review / stock prices

This paper surveys the development of the term "efficiency" in the context of security prices and reviews the principal definitions of "efficiency" that have been proposed, in terms of their likelihood of forming a basis for guiding and evaluating empirical research on the relation between information and prices. It asks what is presently knowable about efficiency, including the conclusions that can and cannot reliably be drawn from the evidence, given the present state of our knowledge about equilibrium security prices. It concludes with a cautious view on the limited reliable evidence concerning "efficiency".

Financial support was provided by the Managerial Economics Research Center at the University of Rochester and the John M. Olin Foundation. Helpf ul comments were provided by Andrew Christie and Jerold Zimmerman. 
In the two decades since the term burst upon the financial economics literature, the "efficient market hypothesis" has stimulated interest and controversy among both researchers and practitioners. The subsequent outpouring of research on the "efficiency" of financial markets (and stock markets in particular) has produced some startling evidence -- both for and against "efficiency." It has become an area of strong but conflicting views.

The early empirical work purported to show that stock prices are unbiased in their reaction to information ${ }^{1}$. This property (unbiased reaction to information) formed the basis of the early, imprecise definitions of "efficiency," which was seen as an implication of rational, maximizing investor behavior in competitive securities markets. The early evidence seemed unexpectedly consistent with the theory. Within a short time of Fama's (1970) influential survey, the growing body of evidence in favor of the efficient market hypothesis had emerged as one of the most consistent and influential empirical areas in economics.

Subsequent work has not reached such consistent conclusions. For example, there is impressive evidence that stock prices systematically under-react to earnings announcements ${ }^{2}$. However, there also is impressive evidence that extreme price changes are in part reversed, which is interpreted by the researchers involved as implying that prices systematically over-react to variables such as earnings announcements ${ }^{3}$. Taken at face value, these findings seem difficult to reconcile. Furthermore, the evidence in each case is relatively uncomplicated and readily discernible to investors, so the apparent inefficiencies imply a relatively disingenious use of information. Yet we have accumulated equally impressive evidence -- unimaginable before the late 1960s -- that stock prices respond in apparently ingenious ways to some categories of information'.

1 Notably, Fama, Fisher, Jensen and Roll (1969) [FFJR] in relation to stock splits and Ball and Brown (1968) in relation to earnings announcements.

2 See the evidence on earnings and dividend announcements surveyed in Ball (1978).

3 See the evidence of De Bondt and Thaler (1985, 1987), including their (1987, sec. II) analysis of earnings reversals.

There is a variety of convincing evidence, some examples of which are given here. (1) Foster (1981) and Clinch and Sinclair (1987) show that earnings announcements are associated with changes in stock prices of other firms in the announcing-firm's industry. (2) Ball (1972) reports evidence that prices do not respond to earnings changes that have been induced by changes in accounting techniques, in the same manner as Ball and Brown (1968) show that prices respond to earnings changes in general. (3) Schipper and Thompson (1983) provide evidence that can be interpreted as prices responding to corporate strategy announcements, rather than waiting until the implementation of the strategy is announced, in the form of acquisition bids. (4) We believe we have learned, from the unexpectedly negative stock price response to new issues, that managers tend to possess private information and to announce new issues when the information suggests that their stock is over-priced. Further, "the market" does not automatically interpret new issues as good news and appears to understand managers' incentives [this evidence is surveyed in Smith (1986)]. These types of results would have been almost unthinkable to even the most market-oriented "pre-efficiency" researcher. 
Reconciliation of the "efficiency" evidence has been complicated by the emergence of extensive "anomalous" evidence in return behavior. The range of evidence is well-known and generally takes the form of uncovering variables (for example, size, day-of-the-week, dividend yield) that are significantly but inexplicably related to security returns. While not directly related to the manner in which prices respond to information (and therefore to "efficiency"), most of this evidence has seemingly defied rational economic explanation and appears to have fundamentally altered researchers' views on stock markets. Taken in its totality, the evidence seems a puzzle.

The "efficiency" literature has produced disagreement in areas other than the evidence. It has produced a variety of research designs, ranging from FFJR's "market model" to Shiller's variance-bounds tests, with some heated debate on their relative merits. The very term "efficiency" has engendered controversy: there is a modest literature, surveyed at length below, on precisely what efficiency means. There even are formal proofs -- whose relevance is disputed by the more empirically-minded researchers -- to the effect that markets cannot be informationally efficient, a priori.

What can we make of all this? Are securities markets efficient? How does one attempt to resolve the now-voluminous body of conflicting evidence? Can conflicting results be explained in whole or in part by differences in research design? What is currently knowable about market efficiency? What is "efficiency"?

My objective is to provoke discussion of these and other questions. I first survey, from an historical perspective, the development of the term "efficiency" in the context of security prices. I evaluate the principal definitions of "efficiency" that have been proposed, in terms their likelihood of forming a basis for guiding and evaluating empirical research on the relation between information and prices. I then focus upon the question of what is presently knowable about efficiency -- that is, what conclusions can and (perhaps more importantly at this point) cannot reliably be drawn from the evidence, given the present state of our knowledge about equilibrium security prices. I conclude with my own views on the efficient markets hypothesis.

\section{Develooment of the Term "Efficient Market"}

The term "efficient" has been used to describe securities markets in a variety of ways over the past two decades ${ }^{3}$. This section discusses the various definitions which have been proposed, with the objective of settling upon a definition that will be used in subsequent sections, which

5 The term consistently has referred to "informational" efficiency, which is a property of the relation between information and securities prices. It has not referred to "production" efficiency (a property of how production is organized) or "exchange" efficiency (a property of consumption markets). See Stiglitz (1981, pp. 236-37) for a distinction. 
review what is knowable about "efficiency". The discussion is organized on a primarily historical basis.

1.1 Early Use of the Term. The term "efficient market" was first used in the context of securities markets by FFJR $(1969$, p.1), who defined it as "a market that adjusts rapidly to new information." The literature on the time series of prices that preceded FFJR had increasingly but heuristically connected its random walk models with competitive markets. Evidence of statistical dependence in security returns was interpreted by this literature as suggesting the existence of unexploited "excess returns", which would be inconsistent with rational investor behavior in competitive markets. Thus, Roberts $(1959$, p.7) tentatively reasoned:

... there is a plausible rationale [for the random walk model]. "If the stock market behaved like a mechanically imperfect roulette wheel, people would notice the imperfections and by acting on them, remove them." This rationale is appealing, if for no other reason than its value as counterweight to the popular view of stock market "irrationality, "but it is obviously incomplete.

FFJR continued the trend in analyzing the securities markets in terms of models that were increasingly economics-based. They cited Mandelbrot (1966) and Samuelson (1965) in linking random walks with "efficiency", they implemented the "market model" with its obvious (but unstated) links with the Sharpe-Lintner capital asset pricing model (CAPM), they extended the information set studied, and they coined (but did not define) the phrase "efficient market". While FFJR pushed empirical research on securities markets significantly closer to mainstream economic theory, they nevertheless provided no explicit development of the "efficient market" theory. The early empirical work thus was increasingly conducted under the belief that it was researching the implications of competitive equilibrium in stock markets, in the context of information use, but it did so without any formal model of this equilibrium.

1.2 Soirit of the Early Work. In extending the information set beyond past prices, to include publicly-available information, FFJR introduced an ingenious research design. As a theoretical construct, "publicly-available" information is that which is accessible to all investors at precisely zero cost. No such thing exists in reality, of course, but a significant subset of all information approximates it. In empirical research, the construct is proxied by announcements in (say) the Wall Street Journal or on the NYSE ticker tape which, while not precisely costless to acquire and 
process subsequent to announcement, are close to being so. ${ }^{6}$ Simple models of competitive equilibrium imply that average revenue from an activity equals its marginal cost. A testable implication of such models is that, if the cost of reproducing public information is zero, then so are the expected gains. Security prices therefore should adjust to information at the first trade after it becomes publicly-available; the gains and losses should be experienced entirely by owners of securities at the time of the announcement; none should be experienced by those who seek to trade on the information.

In contrast, a competitive information market would allow private gains from producing private information and tests of competition would require estimates of the cost of private information production. The central role of public information in the early empirical research on market efficiency thus is easy to explain: the cost of information production is known to be zero, thus allowing a simple and unique test of some of the most basic reasoning in economics. This is the spirit in which I believe the early work was conducted: researchers were simply testing whether the investment world is competitive. However, none of the early researchers chose to go beyond this basic intuition and model the economics involved.

1.3 Fama's Models. Fama (1970) continued the process of formalization. He noted (p. 384) that "to a large extent the empirical work in this area preceded the development of the theory". He defined (p.383) an efficient market as one "in which prices always 'fully reflect' available information" and stated (p.389) the sufficient conditions for efficiency as being: "(i) there are no transactions costs in trading securities, (ii) all available information is costlessly available to all market participants, and (iii) all agree on the implications of current information for the current price and distributions of future prices of each security." His clear intent was to formalize the "fully reflect" notion in terms closer to those of equilibrium pricing theory. Fama was saying that a market is called "efficient" if investors who possess information nevertheless earn a competitive

6 Information processing costs are included because they are part of the costs of reproducing public information. Information acquisition and processing costs should be scaled relative to the value of a stockholding, for comparison with rates of return. For typical "public" information such as announced earnings, any competitive return on such costs would be small relative to (and difficult to detect in) observed rates of return, and is typically assumed away. 
expected return from investing: that is, the information does not alter expected returns. This is the basis of his $E\left(r_{t+1} \mid \sigma_{t}\right)=E\left(r_{t+1}\right)$ definition, equating securities' conditional (on the information set) and unconditional expected returns.

Fama distinguished three nested information sets (past prices, publicly-available information and all information) and correspondingly distinguished the "weak", "semi-strong" and "strong" forms of efficiency. The distinction was not explicitly based on differences in costs of producing information. While it was the first recognition that efficiency must be defined with respect to a particular information set, this approach was not couched in terms of a competitive equilibrium in the market for information about securities. It possibly distracted attention away from the important issue of the costs of obtaining and processing information and from the fundamental economics involved. It also led to ambiguities. Most notably, in Fama's (1970, p.109) introduction he defined efficiency in terms of prices always fully reflecting "available information"; does "available" mean "publicly-available" or does it include information available only to individual investors?

Fama's (1970) modelling seems loose in hindsight, but it served the purpose of early empirical researchers well: they took it for granted that this was a precise enough statement of what they were looking for in the data. I am not aware of any of the important early researchers who thought that further formalization was necessary. It also served to stimulate a definitional debate that has continued for almost two decades. Thus, the modelling and even the concept of "efficiency" began to attract criticism, possibly fueled by: (i) the emergence of information economics as an important field, populated by researchers placing more emphasis upon logical coherence than did the "empiricists"; (ii) the logical scrutiny of the "efficiency" construct that arose naturally from researchers seeking explanations for the early empirical anomalies; and (iii) reactions to Fama's paper. In historical sequence, Rubinstein (1975), Beja (1976), Le Roy (1976), Fama (1976), Grossman (1976), Jensen (1978), Grossman and Stiglitz (1980), Beaver (1981), Jordan (1983) and Latham (1986), among others, have contributed to the debate.

Le Roy criticized Fama's definition on the grounds that it was empty/tautological, because it allowed any feasible set of return distributions to be consistent with "efficiency": the equality of 
conditional and unconditional expected returns is logically feasible in a market that gets them both wrong. In my view, this criticism missed the spirit of Fama's original definition, which intended the unconditional expected return to be its "correct" value ${ }^{7}$. However, Le Roy's criticism demonstrated that the definition could be tightened. Fama $(1976$, p.143) responded with a revised definition in which "the market correctly uses all available information" and thus the joint distribution of future prices established by the market is identical to the "correct" distribution implied by all available information at the time. This definition requires empirical researchers to state or imply something about the "correct" distribution of future prices (that is, to have some way of characterizing a rational, competitive equilibrium, using the CAPM for example), but it is difficult to see how empirical research under any definition of "efficiency" could do otherwise. This revised definition embodied the spirit of Fama's earlier definition and, I believe, of most of the empirical work in the area.

1.4 Further Formalization. At around the same time, a sequence of related works attempted to give even tighter specification to the nature of the equilibrium being contemplated in "efficiency". These works shared a common ancestry. They increasingly framed the efficiency construct in the language, logic and assumptions of the information economics literature.

Rubinstein (1975) canvassed several alternative definitions and commented on their various properties. Sharpe suggested a development of one of these to Beja $(1976$, p.7) and this in turn was further refined by Beaver $(1981$, p.28) as: "market efficiency with respect to an information

7 This can be seen in terms of the empirical work at the time. The "correct" expected return was measured by the regression function prediction $\left(\alpha+2 r_{m}\right)$ of the "market model", which researchers associated, however loosely, with the CAPM. The market model residual (or prediction error) was the difference between the observed return (which by sample construction was conditional upon the information set being studied) and this "correct" return. The efficient-market prediction was a zero sample average post-announcement residual. The discovery of significant non-zero sample average residuals, post-announcement, was taken as evidence that prices had incorrectly responded to the sampled information and that returns had therefore been "incorrect". My interpretation therefore is that Fama intended to model a research process by which observed returns, conditional upon information announcements, were compared with some economically "correct" value, with the market model providing the empirical proxy for "correct" returns. The lesson from this episode is that one can conduct meaningful empirical research in the absence of watertight definitions. 
item means that prices act as if everyone knows that information ${ }^{\text {n8 }}$. More formally, Beaver (p.28) stated:

A securities market is efficient with respect to a signal $y_{t}^{\prime}$ if and only if the configuration of security prices $\left(P_{\mathrm{jt}}\right)$ is the same as it would be in an otherwise identical economy (i.e., with an identical configuration of preferences and endowments) except that every individual receives $y_{t}^{\prime}$ as well as [that individual's own information].

Beaver also provided a more comprehensive definition of efficiency, defined with respect to the system that produces the observed signal and thus with respect to the set of all feasible signais. He termed it "information system efficiency", as distinct from "signal efficiency".

Latham (1986) observed the logical feasibility of information that leads to of fsetting revisions in individual investors' portfolios, without any net effect on excess demand and therefore on prices. For example, information feasibly could cause two investors to make precisely offsetting buy and sell decisions. He therefore defined efficiency relative to some information set "if revealing it to all agents would change neither equilibrium prices nor portfolios" (p.40). The potential advantage of this definition is not this refinement per se, but that it encompasses trading volume and in principle allows a linkage with the empirical work in that area. However, this is of limited use at this point because of our limited insights into the equilibrium determinants of volume (that is, we currently have no way of empirically implementing the "thought experiment" of asking what volume would look like in an "efficient" market, in order to compare it with what we see in the actual markets).

1.5 Comparison of the "Empirical" and "Information Economics" Approaches. The RubinsteinSharpe-Beja-Beaver-Latham sequence develops the efficiency construct down a different intellectual path than Fama's. Most noticeably, Fama (and much of the empirical literature) speaks of the market using information, or of the market establishing prices, whereas the more formal def initions are expressed in terms of individual investors' actions and their relation to prices (and, in Latham's case, volumes). Fama's approach not surprisingly is closer to the empirical traditions of what is sometimes referred to as the "Chicago school" or the "empirical" view; the Rubinsteinthrough-Latham sequence of definitions is closer to the theory-oriented traditions of what is sometimes referred to as the "Berkeley school" or the "information economics" view.

The "Chicago" tradition is frequently described as "pragmatic empirical". It is strongly influenced by the argument, developed in Alchian (1950) and Friedman (1952) among others, that rational, informed, maximizing behavior by all individuals is not a necessary condition for markets to behave as predicted by models which assume such behavior. Under this school of thought, we do not need to fully understand the process by which market prices are formed, in order to build models which successfully "explain" those prices. Accordingly, the process of aggregating from the

Beaver (1981, footnote 11) also attributes the definition to Sharpe, who did not publish it. 
individual to the market is likely to be left as a "black box" under this tradition. ${ }^{9}$ In contrast, the "Berkeley" tradition is more disposed to commence with the individual and then model prices in terms of some aggregation process or property defined over the set of individuals. Thus, Latham (1985, p. 39) motivates his work in part by the observation: "Fama's revised definition, that the market correctly uses all relevant information in determining security prices, is unclear if investors have heterogeneous information, since Fama did not explain what 'the market uses ... the information' would mean in such a case." Yet I am sure that the phrase seems clear enough to researchers operating under the Chicago tradition, certainly when they study prices rather than volumes. Under this tradition the market is personified and is studied in its own right; the market process of aggregating heterogeneous beliefs is not an important issue.

In comparing these approaches, I am biased by my origins toward the empirical viewpoint. I do not believe that the more formal approaches have provided a positive contribution to our understanding of market efficiency, for the following reasons.

First, from an empirical perspective, there is no obvious advantage of the more formal definitions over Fama's (1976) version. It is difficult to see what their definitional refinements contribute to the estimation and interpretation of an "average post-announcement market model residual" in an event study, for example, or to our understanding of the puzzling day-of-the-week seasonals in returns ${ }^{10}$. Researchers never observe the "otherwise identical" world that is central

Rational, calculating, maximizing behavior by all investors is necessary in the more formal theory. In the "empirical" tradition, results are expected to be robust with respect to many violations of this assumption. One version of the argument addresses the very meaning of maximizing behavior. For example, Friedman and Savage (1948, p. 298) employ the metaphor of the billiards player. To "explain" or "predict" the player's behavior, a physicist might assume that the player rationally calculates angles, mass, friction coefficients etc. and processes this information through some physical model of how the ball behaves. But the player need not be a rational physical man in order to succeed: the player acts as if rationally calculating and processing information. Another version of the argument stresses the difference between the marginal and the average investor. Here, the marginal investor determines price and is assumed to maximize and to be informed; uninformed or non-maximizing investors are assumed to be inframarginal and to have an insignificant effect on price.

Treating the process of aggregating from individuals to the market as a "black box" has the advantage that the resulting theory is robust with respect to the foibles of individuals. Conversely, it has the disadvantage of being able to say little about episodes such as October 19, 1987.

10 I disagree with Beaver's (1981, pp.23-24) introductory comment. "Providing a precise definition is a prelude to ... an interpretation of empirical research offered as tests of market efficiency. ... It is difficult to interpret empirical evidence as a test of market efficiency in the absence of a definition of what the concept means". Yet researchers were happy with Fama's (1970) definition, however imprecise it may have been, for some time. They lived with what seems in hindsight an even worse state of affairs before his definition appeared. The reasons, in my view, are twofold. First, researchers had a relatively precise idea of what to expect in the data, even if they did not have an elaborate definitional structure to back their research process up:

(continued...) 
to the refinements that have been proposed by this school of thought; on the other hand, they can attempt to implement a research design that asks whether prices were "correct" with respect to information, by using the post-announcement return predictions of an acceptable model of asset pricing. Being unable to observe the "otherwise identical" world, the practicing empirical researcher has no alternative but to assume that security prices in that world would behave in a "correct" fashion, as predicted by the CAPM for example, and thus is forced to accept a research design that is more directly implied by Fama's (1976) definition. From the viewpoint of empirical research, it is difficult to see what the "otherwise identical world" approach buys us. ${ }^{11}$

Second, from a theoretical viewpoint the more formal models seem to suffer from a conf usion between the properties of information and the properties of markets. Consider their treatment of "publicly-available information". As a construct, this refers to information that is available to all investors at exactly zero cost. The efficiency concept of Latham and predecessors therefore makes all feasible markets tautologically efficient with respect to all genuinely publicly-available information. How would prices ever differ in the "otherwise identical world", in which all investors receive "publicly a vailable" information, which by def inition is already costlessly available to them all in the "real" world? Tautologically, prices cannot differ between these worlds: with exactly zero cost of being informed, all investors in the real world become fully informed about "public" information, by construction. In reality, of course, not all investors can be expected to be costlessly and fully informed about any piece of information, however simple to understand; but this merely says that there is no exact proxy for the construct of public information. Correctly interpreted, it is a statement about information, not market efficiency.

${ }^{10}(. .$. continued $)$

they were looking for evidence that (1) the market responded in an apparently rational fashion to the event being studied; and (2) post-announcement sample average residuals were insignificantly different from zero. Thus, researchers de facto defined "efficiency" in terms of these two properties. Second, the issue of logically coherent definitions was low in priority, relative to getting the empirical work done, and any logical shortcomings in definitions only became apparent later. It appears that the interpretation of evidence is not simply an explicit logical process and that one can collect valuable evidence in the absence of watertight theory. This is not to say that definitional refinement is in any sense unnecessary or counter-productive. The point is that from an empiricist's perspective Beaver's claim is overstated: one can interpret empirical evidence in the absence of a logically refined and coherent set of constructs. See also footnote 7.

11 For purposes of assessing efficiency, the most fruitful area of theoretical research therefore would seem to lie in the development of equilibrium asset pricing models that are capable of explaining some of the more puzzling results that have been observed, rather than in modelling efficiency per se. Since tests of efficiency implicitly or explicitly rely upon such models in order to implement empirical proxies for the notion of a "correct" price distribution (or parameters thereof, such as expected return), empirical work on efficiency seems more likely to be prejudiced by failure in asset pricing models than by not refining the existing definitions of the term. These tasks are not independent, however. 
Conversely, it seems difficult to see under this definition how any market could logically be efficient with respect to any non-public (i.e., privately costly) information. In the spirit of efficiency as a statement about competitive equilibrium, one would expect the construct of "efficiency" to be defined in such a manner as to allow private rewards for private investments in information, including those made by investors, security analysts and corporations themselves. Yet the definition of Latham and his predecessors does not allow this. Private information, if made public in the hypothetical "otherwise identical world", could lead to different prices and perhaps different portfolios, because the supply price of information has been reduced for a set of investors. The "real world" markets thus would be judged "inefficient" with respect to that information -- but only because the information is privately costly to produce, not because of properties of the markets themselves. ${ }^{12}$

Observe that this definition does not allow the real world and the "otherwise identical" world to differ in their market mechanisms (e.g., transactions costs, institutional arrangements such as the quotation mechanism or the dealer system) or in investors' capacities to process information (e.g., tendency to over-react or to react slowly). The worlds are identical except that information is rendered costlessly in the hypothetical world. The comparison is not of real markets with "ideal" markets; it is of information in the real world with costless dissemination of information in an alternative world. The comparison asks the equivalent questions: "Is what we believe to be public or costless information truly costless? Would we change the world if we made it truly costless? Is our proxy for costless information in fact a good one?" This approach therefore amounts to an enquiry into the properties of information, not of markets. The alternative approach, taken in Fama's definitions, is to compare actual with ideal markets.

In sum, the Rubinstein-through-Latham sequence seems to have emphasized logical coherence at the expense of usefulness. It has produced a structure that offers no immediate promise of assisting or even interpreting empirical work on efficiency. It also has defined "efficiency"-which I believe is almost universally interpreted by scholars as a property of markets -- in terms of properties of the cost of information production. This contradicts the spirit of the original "efficiency" concept and of the mainstream empirical literature.

1.6 The Existence of Market Efficiency. Grossman (1976), Grossman and Stiglitz (1980) and Jordan (1983), among others, sought an alternative "efficiency" construct. Grossman and Stiglitz (1980, p.404) cited and rejected Fama's (1970, p.383) definition, that in an efficient market "at any time prices fully reflect all available information". They demonstrated that in such a market there would be no incentive for any individual to produce information, because trading upon it would

12 Owners of valuable private information will not necessarily trade upon it immediately. For example, they might attempt to mingle their trades with those of uninformed liquidity traders, as analyzed in Admati and Pfleiderer (1988). Alternatively, they might have strategic reasons for not risking disclosure of their information. 
costlessly reveal it to others. They offered a reformulation of "efficiency" as a noisy rational expectations equilibrium, the supply-induced noise interfering with investors' ability to infer information from prices. ${ }^{13}$ Prices then cannot "fully reflect all information": without noise, no information is produced, due to lack of incentive; and with noise, prices cannot fully reflect information, because there are uninformed traders. Hence, Fama's definition could not possibly describe any real or hypothetical market. Grossman and Stiglitz thereby highlighted the ambiguity in Fama (1970), referred to in sec. 1.3 above. Whereas Fama referred to prices reflecting "all available information", the fundamental competitive economics predicts only that prices reflect all publicly-available information. Even though there clearly is no incentive to reproduce information that already is publicly-available, there do remain incentives to produce private information in a competitive world. ${ }^{14}$ Part of the confusion appears to be due to Fama's (1970) statistically-based classification of information sets. If the classifications had been based upon the cost of production of information (zero in the case of the so-called "weak" and "semi-strong" forms of the EMH and positive in the so-called "strong" form), then the subsequent confusion might not have arisen. Grossman and Stiglitz' argument thus points out once more the inadequacy of Fama's (1970) original definition, though in fairness to Fama it should be noted that his 1976 revision was by then free of these problems.

Grossman-Stiglitz raises similar issues to those discussed in the previous subsection. An important value espoused by the "empirical school" is that market participants do not need to individually understand the working of a market for it to function well economically. Under this view, observed securities markets could reflect information sufficiently well for researchers to judge them "efficient," yet those same researchers could expect prices to not fully reveal information to all investors.

1.7 Why Does Public Disclosure Occur? Information is revealed to all investors in GrossmanStiglitz through trading by informed investors and its effect on prices. Informed investors act independently, making individual information production decisions. They disclose information to the public only indirectly (and with noise), through their trading. This model omits important institutional solutions to the disclosure incentive problem.

13 In their model, noise takes the form of random per capita supply of the risky asset. This seems highly artificial, particularly in the context of many securities. It seems highly unlikely that there is significant variation in the per capita supply of risky assets (i.e., the market portfolio) between trades of an individual stock, and that this is a significant source of short-term variation in individual stock prices. Subsequent approaches, including Admati and Pfleiderer (1988), introduce liquidity-motivated trading.

14 This can be seen empirically. For example, it is clear from Ball and Brown (1968) that there are gains from obtaining private information on earnings before "the market" does -- that is, before it becomes publicly-available. 
First, firms voluntarily undertake to engage in information production and disclosure to the public, including both actual and potential stockholders. Such undertakings have been included in corporate charters, and thus are a part of their contracts with their stockholders, for six centuries. ${ }^{15}$ Second, stock exchange listing requirements, which are a contract between firms and the exchange and thus also are part of listed firms' contracts with stockholders, typically require firms to disclose important information to the market as a whole (i.e., the public), in a timely fashion. Third, directors have fiduciary responsibilities to stockholders that encompass disclosure, and these also form part of the contract between firms and stockholders. There appear to be no first-order "free-rider" incentive problems under any of these institutional solutions: (1) provided the market is efficient as in Fama (1976), the response of the firm's own stock price to the disclosed information will be captured entirely by its existing stockholders, since all postdisclosure buyers will pay a "fully reflecting" price; and (2) existing stockholders incur the pershare costs of information production and disclosure. Fourth, disclosure laws require firms to produce and disclose information. ${ }^{16}$ These institutional arrangements overlap; for example, disclosure laws regulate what would otherwise be a contract between the firm and its stockholders. None of this rich institutional detail is captured in the Grossman-Stiglitz model, which allows no role for institutions (including firms) and only allows information production to be distributed atomistically and independently among individual investors. Hence, their demonstration that Fama's (1970) efficiency definition fails, due to lack of individual-investor incentives to produce and disclose public information, is not convincing. Public disclosure does occur, but not as a consequence of individuals acting independently.

1.8 Role of Transactions Costs. Jensen (1978, p.96) invokes transactions costs in defining efficiency:

A market is efficient with respect to information set $\sigma_{t}$ if it is impossible to make economic profits by trading on the basis of information set $\boldsymbol{\sigma}_{\mathbf{t}}$. By economic profits, we mean the risk adjusted returns net of all costs. (emphasis added)

A similar definition is implied whenever authors reason along the lines: "the post-announcement excess returns are less than transactions costs, and therefore the market is efficient ${ }^{n} .^{17}$ In my view, this definition is deficient relative to Fama's in several respects.

16 See Watts and Zimmerman (1983).

16 One can argue whether disclosure laws are opportunistic wealth transfers by the political process or attempts to deal with second-order externalities in information production (e.g., the information revealed in one firm's earnings concerning the values of other firms in its industry, as reported in Foster (1981)).

17 An early example of this reasoning is Ball and Brown (1968, pp.173-74), attempting to explain away the first documented "anomaly" in the modern literature: post-earnings-announcement excess returns. 
First, defining efficiency in terms of properties of trading rules rather than properties of markets addresses one of the interesting implications of competitive markets, but it does not address the core issue of how the markets themselves behave. For example, it is logically possible for a market to not "fully reflect" information and that trading rules have not been devised to exploit this, or that investors are subject to regulation that prevents them from trading (this is a different issue than transactions costs, discussed below). To call such a market "efficient", as would Jensen's definition, cuts right across what I believe to be the spirit of the enquiry: that is, that we are investigating whether securities markets work well as competitive, economic institutions. Under this definition, the efficiency of a market is an increasing function of regulatory barriers to the implementation of trading rules, which hardly captures the spirit of the efficiency construct. ${ }^{18}$

Second, I do not see how Jensen's treatment of transactions costs is consistent with the spirit of either the central empirical work in the area or the fundamental motives for studying efficient markets. Consider the following implication of this definition: as the level of transactions costs rises, so does the likelihood that a market will be judged "efficient". In the limit, under this definition, there could be no feasible inefficient market in a world of infinite transactions costs (in the case of sellers, $100 \%$ would suffice), because there could be no trading rules that would generate positive after-cost profits. ${ }^{19}$ This seems absurd: surely we would want to judge no market as efficient in such a world. In my view, the whole point of efficient-markets

18 The current political scrutiny and restriction of program trading" in the U.S. is a case in point. A less extreme example is Indonesia, which has a stock market in which the government establishes prices and approves trades. Prices are revised infrequently and turnover is low. The Indonesian Government reportedly will not permit arbitrage trading (with regulated prices, one is not surprised, since arbitrageurs would defeat the Government's objective of controlling both prices and the identities of shareholders). I cannot imagine that we would want to label this market "efficient". Yet under the Jensen definition, the impossibility of trading rules would make it an "efficient" market.

10 To make sense of the definition, it must be read as referring to the absence of positive after-cost profits. It is trivial in any market to generate negative after-cost profits, simply by increasing the trading frequency. But this creates another problem for this definition. Suppose short selling is banned, as it is in many countries, and a long trading strategy produces negative profits, before transactions costs, suggesting prices that are "too high". Yet, under this definition, the absence of positive profits would cause the market to be labelled "efficient". 
research is to determine whether securities markets act as if they were free of frictions such as transactions costs.

Third, this approach in principle can produce as many definitions of efficiency as there are investors. Transactions costs vary substantially in cross-section. At one extreme, most stockmarkets have brokers or specialists who face negligible costs of transacting. At the other extreme, one can imagine many classes of people who face "large" transactions costs. ${ }^{20}$ Whose transactions costs are to be used in judging the market to be efficient?

Fourth, the correct benchmark for security returns in tests of efficiency is costs of information production, not costs of transacting. A competitive market in the traditional sense acts as if transactions costs are zero. It does not act as if information is a free good. Even published information in reality is not precisely costless, so there will be "small" returns to its use. The issue is whether the returns from information are consistent with its costs.

1.9 Appropriateness of the Term "Efficiency". I know of no evidence that the term "efficiency" was carefully thought out and selected from among alternatives at the outset. It appears to have "caught on" in part because of its convenient juxtaposition with the commonly-held view at the time, that share price behavior was not in any important sense systematic, or capable of orderly economic description. ${ }^{21}$ The term "efficiency" suggested the opposite.

In spite of these origins, the term is curiously appropriate. If prices adjust instantaneously to public information, then at any point in time there will be no future price reaction to old information. Thus, of all feasible prices, those established in such a market offer the minimumvariance distribution of future returns, conditional on public information. In contrast, an "inefficient" market at any point in time need not have completed its price reaction to public information (it might have over- or under-reacted) and hence there would be a component of

20 Examples: elderly, incapacitated people; foreign investors; elderly, incapacitated foreign investors; prisoners; elderly, incapacitated foreign prisoners.

21 For example, when we commenced the research in Ball and Brown (1968), we were confidently advised by our colleagues in other schools and by most of our colleagues in accounting that we should not expect to find any systematic relation between prices and earnings. One accounting practitioner opined that we were "mad". The share market was generally viewed as exhibiting little economic order whatsoever. See also Roberts (1959), quoted above. 
future price variation that is response to old information. Present prices then would not be minimum-variance, or "efficient", with respect to public information. The term thus dovetails nicely with its traditional use, connoting the property of minimum-variance. In this sense, the term "efficient" was selected appropriately (if fortuitously or intuitively).

1.10 Conclusions on Definitions. There have been many attempts to find a suitable definition of market "efficiency".22 Each characterizes market equilibrium with respect to information. One source of difference lies in the type of equilibrium that they characterize. The definitions specify that either:

1. prices are in competitive equilibrium with respect to information; or

2. prices and portfolios are in competitive equilibrium with respect to information; or

3. trading rules defined over a set of information are not profitable, after deducting trading costs.

Most of the more formal literature falls into the first category, commencing with Fama (1970), whereas empirical researchers frequently imply the third type of definition. Research on trading volume increasingly attempts to link with the second approach.

A more striking source of difference in definitions is between the approaches of what I have described as the "empirical" and "information economics" schools. The latter contributions appear to confuse the properties of information with the properties of markets and provide little or no additional guidance to empirical researchers, over and above the former contributions.

It would be preferable to work with constructs that both: (1) are embedded in a welldeveloped, coherent body of theory; and (2) assist in conducting and interpreting a substantial body of coherent empirical research. The second criterion seems more important for the purpose of the following section, which is to discuss the limitations of current empirical methods. Consequently, I shall work with Fama's (1976) definition, which links well with the important empirical literature on efficiency. crisis".

22 Kuhn (1970, p. 71): "Proliferation of versions of a theory is a very usual symptom of 


\section{Limitations on Our Knowledge of Efficiency}

The previous section argues that Fama's (1976) definition of market efficiency is preferred for present purposes over the alternatives in the literature: a market is efficient with respect to particular information if it uses that information "correctly" in setting prices. Implementing that definition requires a theory of, and an empirical measure of, "correct" prices. ${ }^{23}$ This section explores the limitations of our knowledge of what "correct" prices should look like and discusses what these limitations imply for research on market efficiency.

The limitations of available asset-pricing models discussed below are: (1) they address only properties of the exchange of securities, ignoring properties of supply; (2) they are partialequilibrium models and can only address efficiency relative to microeconomic variables; (3) being partial-equilibrium models, they only allow the assessment of the "correctness" of security prices relative to each other, and thus are susceptible to deficiencies in sampling from the population of assets; (4) they assume that it is sufficient to study a parsimonious number of parameters from continuous density functions of future prices; (5) they tend to assume homogeneous beliefs; and (6) they do not address the costs of producing non-public information and therefore do not permit research on efficiency with respect to such information.

Two features of the following discussion should be kept in mind. First, the existence of limits to our knowledge does not in itself imply that insightful research on "efficiency" cannot be conducted. Rather, the implication is that in evaluating the conclusions from any one piece of research, it is essential to examine the sensitivity of those conclusions to imperfections in our understanding of how "correct" prices behave. Second, much of the discussion in this section is uncomfortably intangible and incomplete. If it were possible to formalize the limitations of existing asset-pricing models in a well-developed and coherent fashion, then the ingredients would be available to eliminate the deficiencies. At best, this discussion of fers some loosely-connected

23 This well-known result sometimes is expressed in terms of empirical work being a joint test of efficiency and a particular asset pricing model. Strictly speaking, this is not quite correct. Since the asset pricing models assume perfect markets, which in turn imply efficiency, empirical work involves testing efficiency as modelled by a particular view of asset pricing. It therefore is not a joint test of two hypotheses, but a test of a model of an hypothesis. 
observations about our existing knowledge, to assist in interpreting the expanding body of evidence on efficiency.

2.1 Pure Exchange Models. Essentially all of the techniques of modern Finance address only pure exchange, assuming supply to be determined exogenously. Thus (in historical sequence):

1. The Present Value model addresses the present price of a given future amount, at a given market rate of interest. It is merely an implication of rational investor behavior in perfect securities markets and it does not address the (supply) issue of how the future amount (e.g., a project cash flow) is determined.

2. The Miller-Modigliani theorems address the valuation of firms, given their investment policies and therefore their net cash flows. They also are logical implications of rational investor behavior in perfect securities markets and do not address the (supply) issue of how firms' investment policies and cash flows are determined.

3. The CAPM addresses the valuation of risky securities, given the joint density function of their future values. It also is an implication of rational investor behavior in perfect securities markets and does not address the (supply) issue of how securities' return density functions are determined.

4. The Black and Scholes option pricing model takes pure-exchange reasoning one step further, dealing with securities that are in identically zero aggregate supply and using a purely demand-driven (arbitrage) valuation procedure under the assumption of rational behavior in perfect securities markets. It does not address (nor can it predict the existence of) the supply of traded options.

5. The Arbitrage Pricing Model (APT) is a further extension of pure exchange reasoning. It not only ignores supply; it also seeks to reduce the set of necessary assumptions concerning demand.

The literature has followed a tradition of (and has made its most important breakthroughs by) modelling pure exchange. Failure to model the supply of securities quite possibly is the greatest deficiency in modern Financial theory. ${ }^{24}$

One consequence of not explicitly modelling supply is the implicit assumption that supply parameters are constant. For example, consider the notorious day-of-the-week seasonal in stock returns. ${ }^{25}$ Evidence of time-varying average returns so startled researchers, raised on a diet of constant expected returns, that a voluminous literature quickly developed. The particularly startling result has been significantly negative average returns on weekends. When supply factors are considered, it is not clear that these results should be surprising. In a competitive world, market returns should equal the marginal efficiency of investment (MEI) over every interval, no

24 The efficient market hypothesis itself is a pure-exchange approach: it asserts that, given the supply of information, rational behavior in perfect securities markets will have certain implications. It does not address the supply of information.

${ }^{26}$ For example, see Cross (1973) and Rogalski (1984). The argument in this paragraph is expanded in Ball and Bowers (1988). 
matter what its length. This holds for days, nights and weekends. However, we possess no supply-side theory of how the MEI varies over time (e.g., how Mondays differ from Thursdays). Casual observation does suggest that the MEI on weekends is lower than on weekdays, and possibly is negative (assets are idle and incur positive holding costs). ${ }^{26}$ Mondays are said to have higher work absenteeism than other weekdays, with possibly lower MEI. Nights presumably are less productive than days (though in an international market, the notion of a night is not welldefined). These are no more than stylized facts, but they serve to illustrate the point: observed returns feasibly could exhibit any seasonal pattern, in the absence of theory that places bounds on supply seasonals. In pure-exchange models, which by construction cannot impose such bounds, what seasonal pattern of returns could possibly surprise us per se? What possible implications concerning market efficiency can we draw from observed day-of-the-week seasonals? If the best knowledge we have is stylized facts rather than theories, surely our priors must be influenced by those stylized facts and we must expect daily seasonals in a competitive market.

A second example is provided by our lack of theory on the determinants of CAPM parameters. The CAPM is a very simple pure-exchange model and takes the market portfolio variance, the market risk premium and individual assets' betas as exogenously given. These parameters certainly will not be time-series constants, and in the simple world of the CAPM they could feasibly exhibit any pattern of variation over time. What level of variance in the observed market index could we possibly accept as evidence of efficiency or inefficiency, using pureexchange logic? ${ }^{27}$ What variation over time in the index variance is acceptable? Our theories of asset pricing are silent on these issues, the implication being that we cannot reliably test market efficiency in any research design that is sensitive to substantial variation in asset pricing parameters. This seems to rule out many research designs, especially those using data over an extended period. In particular, I cannot see what logical inference concerning market efficiency can be reliably drawn from Shiller $(1981 \mathrm{a}, \mathrm{b})$ and related designs. His data certainly present an

36 There is no feasible arbitrage across time that forces returns in any low-MEI interval toward some time-series mean. In particular, it is incorrect to argue that prices always adjust to yield a positive expected return, because there is no guarantee of a natural, positive discount rate at all points in time. Note that the above argument refers to the marginal, not average, efficiency of investment and does not require, for example, that all investment assets be idle on weekends. Marginal productivity seems likely to exhibit more seasonal variability than average productivity.

This reasoning shifts the anomaly to the seasonal in the risk premium, since it does not explain positive weekend interest rates. See Ball and Bowers (1988).

${ }^{27}$ For example, consider a perpetuity of expected real cash flows. Let the real riskless rate be zero, which is close to its historical average. An increase in the risk premium (which here equals the real discount rate) from $6 \%$ to $8 \%$ will reduce the perpetuity's price by $25 \%$, holding expected cash flows constant. If expected real cash flows are negatively correlated with the real discount rate, then the fall in price will be greater than $25 \%$. Is this magnitude of price change too large for "efficiency"? Too small? How can we tell from the models we use? 
intriguing puzzle, but I do not see how they relate to the efficiency of markets, unless one is prepared to accept his extraordinary assumption (1981a, p. 292) that the nominal discount rate is a time-series constant over the sample period 1871-1979.

To illustrate the limitations involved when supply is ignored, consider the following conjecture. Investors are risk-averse and hence the expected market return on risky assets is an increasing function of the aggregate supply of risk (measured by the standard deviation of future wealth). The aggregate supply of risk is the product of the quantity of risky assets and the uncertainty of the rate of return on risky assets. Uncertainty is a random variable, perhaps following a moving-average process, determined by investors' perceptions of political and economic stability. The supply of risky assets is less elastic in the short term than the long, because it takes time to create new assets and for existing assets to become economically obsolete. There then will be sequences in which, especially over long periods, returns are not stationary. For example, a period of unexpected stability will be associated with increases in equity prices, and thus with positive ex post returns, as the discount rate falls. Until supply adjusts, ex ante returns will be relatively low, reflecting decreased uncertainty. Supply then will increase over time, as firms create new investments in response to the lower cost of capital (i.e., increased "confidence"). Supply increases will cause yields to rise, because risk-averse investors now bear an increased aggregate supply of risk. The rate at which this occurs depends upon the speed with which new investments can be created. The sequence of high-low-increasing returns will be an equilibrium response to the unexpected reduction in uncertainty. (An equivalent sequence will occur in response to increases in uncertainty). The point of this conjecture is to illustrate that supply characteristics influence the sequence of returns that one would expect in an "efficient" market. Without supply-side theory (i.e., in a pure exchange framework), it is difficult to see how we could be surprised by any observed sequence of market returns. It also is difficult to see how we could use the observed sequence to judge any market to be efficient or inefficient.

Similarly, pure-exchange theory is silent on how betas vary in cross-section and across time. What observed betas and what temporal variation in observed betas will we accept as consistent with efficiency? ${ }^{28}$ For example, the betas of the fifty extreme "losing" stocks in De Bondt and Thaler (1987) can be expected to be large (relative to the betas of the firms' assets and of other firms' stocks) and highly variable (relative to the betas of successful firms' stocks), the reason being the extreme increase in their market-valued debt/equity ratios. In general, the beta of a firm's equity, given the beta of its assets, is a function of its debt/equity ratio, which varies with

28 These parameters could exhibit seasonals also: there is no reason in principle why aggregate risk and securities' relative risks cannot vary with (say) day-of-the-week. Consider a firm that routinely makes its major announcements -- earnings, dividends, investments, acquisitions -- on Thursdays, perhaps because it schedules board meetings on that day. Thursday returns then will exhibit higher variance and, possibly, covariance. 
every realization of the historical return on equity. Equity betas therefore vary every period, given asset betas. ${ }^{29}$ Conventional methods of parameter estimation tend either to assume stationarity over extended periods (measured relative to the periodicity of the feasible nonstationarities) or to restrict the allowable non-stationarities. It is not clear that they can capture the non-stationarities one would expect in the data.

Overall, empirical work in securities markets tends to use models that say little about where to expect non-stationarities, and use data and estimation techniques that could easily disguise them. In the circumstances, I am not convinced that we can reliably conclude much about "efficiency" as an empirical fact whenever we use research designs that are sensitive to nonstationarities. This applies particularly to analyses of returns over long periods. ${ }^{30}$

2.2 Partial-Equilibrium Models. The available asset pricing models not only ignore supply: they are incomplete statements about demand. The CAPM is a simple extension of the Present Value model to a mean-variance world. As such, it is a pure-exchange statement about the pricing of securities relative to each other: it simply adjusts the "equal rate of return" rule, which is the present value model, for differences in securities' (exogenously-given) risks. The partialequilibrium characteristic of the CAPM is manifested in the role of the market portfolio, or index: each security is priced relative to the index, the expected return on which is taken as exogenous. Consequently, tests of efficiency currently cannot be conducted in a CAPM framework on information that is correlated with the market index; we have no model of the "correct" expected return on the index itself.

Consider, for example, the information that the central bank will double the money stock one year hence, with probability one. At what level would an efficient market establish the index today? The answer to that question lies in macroeconomic theory, which is not unanimous. It is tempting to answer that prices immediately rise in full anticipation of the money stock doubling, but that assumes that the nominal discount rate is independent of changes in the money stock. At the other extreme, if the real discount rate is to remain constant instead, then the index does not change now: it changes one period hence, and the nominal discount rate over the next year increases instead. Intermediate solutions are feasible: if money influences real variables, then both the nominal and the real rates change, and the index immediately changes to some intermediate point. Which of these three responses occurs in an efficient market depends upon what one's

20 See Cox and Rubinstein (1985, pp.185-196) for a discussion that applies to the case of risky debt. De Bondt and Thaler (1987, p.564) recognize the varying-leverage problem, but do not provide a convincing procedure for detecting the short-run variation in equity betas that the Black and Scholes analysis predicts. Note that, due to leverage, betas and therefore expected returns are a decreasing function of realized past returns -- which is consistent with the negative serial correlation observed in Fama and French (1988).

so Fama and French (1988) report evidence relevant to the issues discussed in this subsection. 
theory of a "correct" price response to variation in the money stock. The point of the example is that the CAPM provides no insights in this context, because it takes the market return as exogenously given.

In the context of the CAPM and the "market model", we therefore can obtain at best a partial assessment of efficiency with respect to information that is correlated with the market index, because the index itself contains part of the market's reaction. ${ }^{31}$

2.3 Limitations of A vailable Data. Most tests of market efficiency have been conducted on prices and returns for listed securities, due to limited availability of reliable data for other assets. The tests exclude or substantially under-represent investments in small businesses (sole proprietorships, partnerships, private corporations), human capital, personal property (houses, land, cars), corporate debt and public assets. It is well-known that these data limitations can lead to distorted estimates of important parameters, at least in the context of the CAPM. ${ }^{32}$ They therefore are capable of distorting estimates of excess returns and, in turn, of market "efficiency". This is not a simple problem of a non-representative sample of assets; because we rely upon partial-equilibrium models which attempt to describe the pricing of assets relative to each other, it is a problem of evaluating a non-representative sample against a non-representative benchmark. Any resulting biases would most likely be strongest for small stocks, since they are where the benchmark (in the CAPM, this is the "market index", which is the sample average listed stock) is least representative. Most large, private assets are listed and thus the index, which is dominated by such assets, is an effective control group for individual members of this class. In contrast, the smallest listed stocks are the closest substitutes for unlisted assets that are omitted from the market portfolio, and the index is a poorer control group. Their "true" betas could be substantially different than those estimated from indexes of listed stocks. In general, the benchmark used in implementing a partial-equilibrium model, such as the CAPM, is most likely to be deficient in evaluating excess returns on the stocks which are the least comparable to it. We thus seem least able to reliably infer efficiency, or inefficiency, in relation to the smallest stocks.

2.4 Distributional Assumotions. The notion that securities can be described in terms of a small number of parameters of a continuous, joint probability density function of future values, is an intellectual abstraction. Useful as it may be, it is an abstraction. Tests of efficiency are limited by the extent to which the abstraction is valid.

For example, typical market model "event studies" assume a mean-variance world. How frequently is a sample average residual dominated by a small number of outliers, in cross-section

31 This explains why Ball and Brown (1968) orthogonalized their EPS variable with respect to an "market" index of firms' EPS, prior to investigating the relation between EPS and security prices.

32 Roll $(1977,1978)$ first demonstrated this problem. 
or in time? How will future researchers handle the data from 19 October 1987 and the surrounding high-volatility days, which will dominate conventional parametric estimators? The choices include: (1) allow that subperiod to dominate the results; or (2) adopt a procedure that has the effect of throwing away much of the information contained in that episode, such as excluding it as an outlier, or using estimators that reduce its relative weight, or using non-parametric estimators; or (3) attempt models that incorporate such episodes.

The CAPM provided a major insight into the pricing of risky securities. Nevertheless, it is a very simple model, assuming that investments differ only in risk and that risk can be described in terms of second moments of continuous density functions. It thus provides a limited benchmark for assessing whether the market "correctly" sets prices.

2.5 Heterogenous Beliefs. Available asset-pricing models typically assume homogeneous beliefs, which also is an abstraction. This issue was discussed in 1.5 above; its implications for tests of efficiency, including possible volume tests, are not clear.

2.6 Costs of Producing Non-public Information. There are no developed models of private information production which permit tests of whether that activity in general is competitive. For example:

1. If a security analyst specializes in 10 stocks at an average annual cost of $\$ 20,000$ (including salary and overheads) each, for clients with an aggregate investment of $\$ 20$ millions, the expected increase in private return is in the order of one-tenth of one percent. Can we reliably detect such a low number in stock returns?

2. If 1,000 professors of Finance worldwide incur costs of $\$ 50,000$ each (including salary and overheads) in searching for anomalies, should the expected value of the private return from discovering pricing errors in the market be in the order of $\$ 50$ millions per year? This is equivalent to $5 \%$ per year on a $\$ 1$ billion portfolio. If they have been incurring search costs for 20 years, what is the expected private return?

3. Why have some researchers published their anomalous evidence? Why have we not all used the information for private gain?

4. What is the predicted size of gains from "inside information"?

These are interesting questions, but we have no well-developed insights into their solution. To date, we understandingly have relied upon publicly-disclosed information, which by definition is privately costless, for our tests of efficiency.

2.7 Summary. It is well-known that tests of efficiency rely upon particular implicit or explicit assumptions concerning equilibrium asset pricing. This section has discussed a range of possible limitations of the available models of asset pricing, together with their possible effects on tests of efficiency. The range of limitations is impressive, to the point where it is tempting to conclude that we can gather little, if any, reliable evidence concerning market efficiency. But that would be too pessimistic. What can we conclude? 


\section{Are Stock Markets Efficient?}

The "efficient market hypothesis" now is approximately two decades old, the expression having been coined and the initial empirical work having been completed in the late 1960s. Its second decade has been remarkably different than the first, having been plagued by anomaly and uncertainty. Can we conclude from the evidence that stock markets are (or are not) efficient? What is the future of the hypothesis?

There is no doubting that the early empirical literature on market efficiency has had an enduring impact. "Efficiency" was seen from the outset as a property of competitive securities markets. In the late 1960 s and early 1970s this was an unusually successful area for empirical research in economics. It was one of the few areas in which a very large amount of data could confront a simple, testable hypothesis that derived from the competitive economic paradigm. ${ }^{33}$ And the paradigm appeared to work: stock markets consistently seemed to be efficient. Because this evidence tended to contradict priors, which seem to have been based on prejudice and casual observation of the markets rather than on systematic research, academic attention was quickly drawn to it. ${ }^{34}$ Furthermore, the early work on "efficiency" coincided with the emergence of interest in and respect for markets in general among economists. The early empirical work therefore assumed importance and attracted interest beyond its direct implications for stock markets. It influenced the worldwide move toward "liberalizing" financial and other markets.

There also is no doubting the subsequent accumulation of a variety of anomalous evidence, directly or indirectly calling "efficiency" into question. The documented anomalous price behavior included apparent under-reaction, apparent over-reaction and puzzling variation of prices with dayof-the-week, size, dividend yield, earnings yield and other variables that have been difficult to rationalize economically.

Why did the evidence appear to change so drastically? One reason is that the earlier researchers tended to "sweep the evidence under the rug", until its accumulated weight could not be ignored. Perceptions of the existing evidence then changed almost overnight. ${ }^{35}$ A second

28 The data were unusually plentiful. In the case of the New York Stock Exchange, the world's largest, CRSP provided comprehensive data on the universe of stocks -- an almost unheard-of luxury among economists. In addition to being plentiful, the data were essentially error-free and came in machine-readable form, which was rare at the time.

34 Harry Roberts' (1959, p.3) musings seem well-justified in hindsight: "What slight departures from the chance [random walk] model are detectable? Perhaps the traditional academic suspicion about the stock market as an object of scholarly research will be overcome ... ."

$35 \mathrm{Kuhn}(1970)$ describes this as a normal initial response to anomaly. Personal experience is consistent with this response: the survey of earnings anomalies in Ball (1978) took over two years to get published; and even then publication awaited the accumulation of enough anomaly to fill a special issue of the journal. While the anomalous evidence had been quietly accumulating for a decade, researchers were reluctant to confront it until it was abundantly clear. 
reason is that our research techniques have progressed. We now have: larger data bases (covering more securities and longer time periods); improved statistical techniques; and computational costs that are orders of magnitude lower than in the first decade of the EMH. Consequently, previously-undetected anomalies now are more likely to be observed. In addition, the nature of the research conducted has shifted systematically over time, into areas where anomaly is more likely a priori. The early empirical studies investigated stocks and events that were less extreme than in the studies that followed. Earnings changes, for example, are "normal" events: every NYSE firm experiences one earnings change, every quarter. Investigating the relation between stock prices and simply the sign of earnings changes -- without regard to the magnitude of the change, the size of the corporation, the day or month of the announcement, etc. -- involves studying normal events for normal firms. The market portfolio (i.e., the average firm) thus provides a reasonable control for a portfolio of firms that experience earnings increases, or for a portfolio of earnings-decreasing firms. The control is not perfect, but it is effective; there is not much anomalous return behavior. After the more common information sources such as earnings have been exhausted, researchers have turned to increasingly uncommon phenomena in search of new topics. As time has progressed, researchers have tested "efficiency" (and, therefore, explicit or implicit models of price equilibrium) against progressively more-extreme phenomena, investigating such things as returns on the very smallest stocks on the very first trading day of the year, or on the most extreme "losers" in the market over an interval in time, or on the most extreme stocks in terms of earnings performance or earnings yield. These research designs presumably are more sensitive to misspecifications in our models of market equilibrium. However, models of asset pricing have not kept pace with the requirements of this research, which increasingly finds them breaking down. All factors considered, one should expect increasing problems.

Testing a paradigm in successively more-rarified circumstances is "normal" behavior in the progress of science: we first "sharpen" our expectations upon the more routine research designs and we then try them against the extremes. ${ }^{36}$ It is here that we are most likely to discover novel insights. But where will this lead us? Will we abandon the "efficient market hypothesis", as some commentators have suggested?

Kuhn $(1970, p .84)$ states that scientific communities have three generic responses to repeated anomaly:

36 Kuhn's (1970, pp.86-87) description fits the "efficiency" literature well: "Faced with an admittedly fundamental anomaly in theory, the scientist's first effort will of ten be to isolate it more precisely and to give it structure. Though now aware that they cannot be quite right, he will push the rules of normal science harder than ever to see, in the area of difficulty, just where and how far they can be made to work. Simultaneously he will seek for ways of magnifying the breakdown, of making it more striking and perhaps also more suggestive than it had been when displayed in experiments the outcome of which was thought to be known in advance." 
[A]ll crises close in one of three ways. Sometimes normal science ultimately proves able to handle the crisis-provoking problem despite the despair of those who have seen it as the end of an existing paradigm. On other occasions the problem resists even apparently radical new approaches. Then scientists may conclude that no solution will be forthcoming in the present state of their field. The problem is labelled and set aside for a future generation with more developed tools. Or ... a crisis may end with the emergence of a new candidate for paradigm and with the ensuing battle over its acceptance.

Response to the barrage of "efficiency" anomalies depends in part upon the nature of the evidence presented. To evaluate the evidence, one in turn must evaluate the models, techniques and the data employed.

Tests of "efficiency" are well-known to be tests of particular models of equilibrium pricing with respect to information. They therefore are limited by our meager understanding of what an equilibrium in the securities markets would resemble. We saw in sec. 2 that the available models of equilibrium security pricing tend to: describe pure exchange, ignoring supply (e.g., tell us nothing about "betas" and how they might vary across time, including short intervals); be silent about seasonality (e.g., not state or imply anything to distinguish days of the week from each other); describe a partial equilibrium only (e.g., treat as exogenous all "macro" parameters, such as the expected return on the "market" portfolio); assume homogeneity of beliefs; assume that return distributions are continuous and described by a small number of parameters; and ignore costs of private information production. They thus have major inherent limitations in describing the world and in forming the basis for deciding whether markets are "efficient". Leaving aside the Present Value model, our models of pricing equilibrium began with the CAPM and thus have an accumulated history of only 25 years. With such a limited tradition in asset pricing, we could hardly expect to have a strong basis for concluding that security prices do (or do not) immediately restore equilibrium, conditional upon information flows, particularly when they are taken to the extreme.

In addition, it is worth examining the nature of the data that are available for estimating parameters of these models. In sec. 2.3 above, we discussed some effects of the data limitations, as first observed by Roll $(1977,1978)$. These effects are likely to be strongest among small 
stocks, implying that on data availability grounds alone we might not be able to draw reliable conclusions concerning efficiency from small-stock returns.

A problem that lies at the intersection of theory and data is non-stationarity. There is nothing in the asset-pricing models that bounds the degree of non-stationarity that can be expected in their parameters. We can only search for it in the data, without theory to guide us. This applies to CAPM parameters such as the variance of the return on the market portfolio, the risk premium and stocks' betas. Non-stationarities can be short-term as well as long term, and thus can be difficult to observe from time-series data. They severely restrict the range of reliable research on market efficiency.

Bearing all these limitations in mind, I personally believe that much of the evidence on stock price behavior does not and cannot reliably address the issue of "efficiency" at this point in time: our models of price equilibrium and our data are too limited. ${ }^{37}$ Conversely, the most reliable evidence for evaluating "market efficiency" is that which relies less upon particular models of price equilibrium and precise pricing benchmarks such as the market index. It therefore is research that does not involve extreme securities, events or time periods.

Returning to Kuhn's three generic responses to repeated anomaly, my bet is on the first or the second. I expect to see some of the anomalies being resolved after further research and some of them being shelved. I do not envisage theories built around market inefficiency receiving widespread support, for several reasons. First, stock markets must rank highly among markets on a priori likelihood of being competitive: there are no entry barriers; there are many buyers and many sellers, who by and large appear to be greedy, avaricious, inventive people; and transaction costs are low. Second, as outlined above, limitations of our models of "correct" pricing and of the available data seem the most likely sources for the impressive range of anomalies that have been documented over the last decade. In the earlier research, where the designs were less sensitive to model and data imperfections, "efficiency" performed relatively well. Third, I personally went

37 This is not to say that empirical research cannot be informative under these circumstances. We have learned a considerable amount from the "anomaly chasing" of the last decade; and there are enough puzzles and clues to work on for some time. However, I do not believe that we can reliably learn much about efficiency from these results. 
through the transformation from the pre-EMH view of securities markets, and I am still impressed by how well prices respond to information, relative to what we expected two decades ago.

\section{Conclusions}

Conclusions from a selective review of this kind inevitably reflect one's biases. My personal views can be summarized as: (1) the efficient market hypothesis was an audacious and welcome change from the ignorance of stock markets that preceded it; (2) a priori, stock markets are paradigm examples of competition and thus of "efficiency" in using information; (3) there are binding limitations in our knowledge of what price behavior to expect in an "efficient" market, so in turn there is limited reliable evidence on "efficiency"; (4) the evidence collected over the past twenty years must have shifted a reasonable person's beliefs toward "efficiency"; (5) to a large degree, the anomalous evidence shows up where one would expect it: where research designs are most sensitive to limitations in our knowledge of asset pricing; (6) the anomalous evidence provides an intriguing set of puzzles for researchers to solve; and (7) given the priors expressed in (2) above, I expect many (though certainly not all) of the anomalies to be resolved in favor of efficiency. 


\section{References}

Admati, A.R. and P. Pfleiderer, 1988, A theory of intraday trading patterns: Volume and price variability, Review of Financial Studies, forthcoming.

Alchian, A., 1950, Uncertainty, evolution, and economic theory, Journal of Political Economy 58, 211-221.

Ball, R., 1972, Changes in accounting techniques and stock prices, Empirical Research in Accounting: Selected Studies, supplement to Journal of Accounting Research, 1-38.

Ball, R., 1978, Anomalies in relationships between securities' yields and yield-surrogates, Journal of Financial Economics 6, 103-126.

Ball, R. and J. Bowers, 1988, Daily seasonals in equity and fixed-interest returns: Australian evidence and test of plausible hypotheses, in: Stock market anomalies, ed. E. Dimson (Cambridge University Press).

Ball, R. and P. Brown, 1968, An empirical evaluation of accounting numbers, Journal of Accounting Research 6, 159-178.

Banz, R.W., 1981, The relationship between return and market value of common stocks, Journal of Financial Economics 9, 3-18.

Beaver, W.H., 1981, Market efficiency, The Accounting Review 56, 23-37.

Beja, A., 1976, The limited information efficiency of market processes (University of California, Berkeley).

Black, F. and M. Scholes, 1973, The pricing of options and corporate liabilities, Journal of Political Economy 81, 637-654.

Clinch, G.J. and N.A Sinclair, 1987, Intra-industry information releases: A recursive systems approach, Journal of Accounting \& Economics 9, 89-106.

Cox, J.C. and M. Rubinstein, 1985, Options markets (Prentice-Hall, Englewood Cliffs).

Cross, F., 1973, The behavior of stock prices on Fridays and Mondays, Financial Analysts Journal 29, 67-9.

De Bondt, W.F.M. and R.H. Thaler, 1985, Does the stock market overreact?, Journal of Finance, 793-805.

De Bondt, W.F.M. and R.H. Thaler, 1987, Further evidence on investor overreaction and stock market seasonality, The Journal of Finance 42, 557-581.

Fama, E.F., 1970, Efficient capital markets: A review of theory and empirical work, Journal of Finance 25, 383-417.

Fama, E.F., 1976, Foundations of finance (Basic Books, New York).

Fama, E.F., L. Fisher, M.C. Jensen and R. Roll, 1969, The adjustment of stock prices to new information, International Economic Review 10, 1-21. 
Fama, E.F. and K.R. French, Permanent and temporary components of stock prices, 1988, Journal of Political Economy 96, 246-273.

Fama, E.F., and M.H. Miller, 1972, The theory of finance (Holt, Rinehart and Winston, New York).

Foster, G., 1981, Intra-industry information transfers associated with earnings releases, Journal of Accounting and Economics 3, 201-232.

Foster, G. C. Olsen and T. Shevlin, 1984, Earnings releases, anomalies, and the behavior of securities returns, Accounting Review 59, 574-603.

Friedman, M., 1952, The methodology of positive economics, in: Essays in Positive Economics (University of Chicago Press, Chicago).

Friedman, M. and L.J. Savage, 1948, The utility analysis of choices involving risk, Journal of Political Economy 56, reprinted in: Readings in price theory, American Economic Association. (Richard D. Irwin, Inc., 1952, Chicago) 57-96.

Grossman, S.J., 1976, On the efficiency of competitive stock markets where traders have diverse information, Journal of Finance 31, 573-585.

Grossman, S.J., and J.E. Stiglitz, 1980, On the impossibility of informationally efficient markets, American Economic Review 70, 393-408.

Jensen, M.C., 1978, Some anomalous evidence regarding market efficiency, Journal of Financial Economics 6, 95-101.

Jordan, J.S., 1983, On the efficient markets hypothesis, Econometrica 51, 1325-43.

Kuhn, T.S., 1970, The structure of scientific revolutions (The University of Chicago Press, Chicago).

Latham, M., 1986, Information efficiency and information subsets, Journal of Finance 41, 39-52.

Le Roy, S., 1976, Efficient capital markets: A comment, Journal of Finance 31, 139-141.

Lintner, J., The valuation of risk assets and the selection of risky investments in stock portfolios and capital budgets, Review of Economics and Statistics 47, 13-37.

Miller, M.H., and F. Modigliani, 1961, Dividend policy, growth and the valuation of shares, Journal of Business 34, 411-433.

Roberts, H.V., 1959, Stock market 'patterns' and financial analysis: Methodological suggestions, Journal of Finance 14, 1-10.

Rogalski, R., 1984, New findings regarding day of the week returns over trading and non-trading periods: a note, Journal of Finance $39,1603-1614$.

Roll, R., 1977, A critique of the asset pricing theory's tests; Part 1: On past and potential testability of the theory, Journal of Financial Economics 4, 129-176.

Roll, R., 1978, Ambiguity when performance is measured by the security market line, Journal of Finance 33, 1051-1069.

Rubinstein, M., 1975, Securities market efficiency in an Arrow-Debreu economy, American 
Economic Review 65, 812-824.

Samuelson, P.A., 1965, Proof that properly anticipated prices fluctuate randomly, Industrial Management Review 6, 41-49.

Schipper, K., and R. Thompson, 1983, Evidence on the capitalized value of merger activity for acquiring firms, Journal of Financial Economics 11, 85-119.

Sharpe, W.F., 1964, Capital asset prices: A theory of market equilibrium under conditions of risk, Journal of Finance 19, 425-442.

Shiller, R.J., $1981 \mathrm{a}$, The use of volatility measures in assessing market efficiency, Journal of Finance 36, 291-304.

Shiller, R.J., $1981 \mathrm{~b}$, Do stock prices move too much to be justified by subsequent changes in dividends?, American Economic Review 71, 421-436.

Smith, C., 1986, Investment banking and the capital acquisition process, Journal of Financial Economics 15, 1/2, 3-29.

Stiglitz, J.E., 1981, The allocation role of the stock market: Pareto optimality and competition, Journal of Finance, 235-51.

Watts, R. and J. Zimmerman, 1983, Agency problems, auditing and the theory of the firm: Some evidence, Journal of Law and Economics 26, 613-634. 
$+$

$\therefore$ 